\title{
Infuence of Light-Curing Units on Color Stability of Composite Resins After Aging
}

\author{
A Fakhari ${ }^{1}$, Heshmat $^{2}$, M Emami Arjomand ${ }^{3}$, SF Tabatabaei ${ }^{*} 4$ \\ 1-Dentist, Tehran,Iran
}

2- Associate professor, Restorative Dept and Dental material research center, Faculty of Dentistry, Tehran Medical

Sciences, Islamic Azad University, Tehran, Iran, Islamic Azad University, Tehran, Iran

3- Assistant professor, Restorative Dept and Cosmetic Dentistry, Faculty of Dentistry, Tehran Medical Sciences,

Islamic Azad University, Tehran, Iran

4- Assistant professor, Department of Restorative and Cosmetic Dentistry ,Semnan University of medical sciences, Semnan, Iran

\begin{tabular}{l}
\hline ARTICLE INFO \\
\hline Article History \\
Received: Nov 2019 \\
Accepted: Dec 2019 \\
ePublished: Feb 2020 \\
Corresponding author: \\
SF Tabatabaei, Assistant \\
professor, Department of \\
Restorative and Cosmet- \\
ic Dentistry ,Semnan \\
University of medical \\
sciences, Semnan, Iran \\
Email: farnaztabata- \\
baei96@gmail.com
\end{tabular}

\section{Introduction:}

In recent years, the use of composite restorations has increased due to the increasing demand for cosmetic treatments, the ease of bonding processes, the improvement of composite properties, and the advancement in their fabrication. ${ }^{(1)}$ One of the most important problems with composite restorations is the loss of consistency between the composite and tooth color over time.

\begin{abstract} ( $\mathrm{P}=0.474)$. color change compared to QTH.
\end{abstract}

Background and Aim: One of the most important problems with composite restorations is the loss of consistency between the composite and tooth color. The present study aimed to compare the color stability of two types of nanohybrid composites cured with different light-curing devices after aging.

Materials and Methods: In this study, the color stability of 40 disc-shaped specimens (10 $\mathrm{mm}$ in diameter and $2 \mathrm{~mm}$ in height) from two types of enamel and dentin nanohybrid composites (IPS Empress Direct, Ivoclar Vivadent) was investigated. A group of 10 samples of each composite was cured by light-emitting diode (LED) Bluephase device (Ivoclar, Vivadent) at $1200 \mathrm{~mW} / \mathrm{cm} 2$ for 20 seconds, and another group of 10 specimens was cured by a quartz-tungsten-halogen (QTH) device (Coltolux 2.5, Colten, USA) at $600 \mathrm{~mW} / \mathrm{cm} 2$ for 40 seconds. The initial color of the samples was determined by the Konica Minolta spectrophotometer (CS2000, USA), and then, the composite samples were subjected to an accelerated artificial aging (AAA) process in the QUV/SPRAY device. Then, the color of the samples was reassessed. Two-way analysis of variance (ANOVA) was used to compare the color changes in the study groups at a significance level of $\mathrm{P}=0.05$.

Result: The specimens cured by the LED device showed significantly lower color change compared to QTH $(\mathrm{P}=0.047)$. However, there was no significant difference in color stability between enamel and dentin composites cured by a fixed apparatus

Conclusion: The curing of nanohybrid composites with LED devices causes lower

Keywords: Aging, Composite Resins, Dental Curing Light, Spectrophotometry

\section{J Res Dent Maxillofac Sci 2020;5(2):21-25}

As a result, the most important advantage of composites, which is the provision of beauty, will be lost. In most cases, discoloration requires the replacement of the restoration, which is time-consuming and costly with possible loss of tooth structure. ${ }^{(2)}$ The color stability of resin composites depends on several internal and external factors. 
Internal factors include composite resin composition such as monomer chemistry, filler composition, filler type, initiators, and inhibitors. ${ }^{(3)}$ One of the most important factors affecting the color stability of composite resins is the amount of composite polymerization. The type of lightcuring device is one of the most important factors affecting the composite polymerization rate. ${ }^{(4)}$ The widespread use of composites has led to the advancement of light-curing devices and the supply of more efficient devices. Halogen devices have been used for curing composites for many years. $^{(5)}$ In 1990, light-emitting diode (LED) devices were launched. Due to the longer life of LED devices, lower power consumption, no need for regular lamp replacement, and ease of use, the general tendency to use them is increasing, and quartz-tungsten-halogen (QTH) devices are replacing LED devices. ${ }^{(6)}$

Given the increased efficiency of LED devices and the importance of color stability of composite restorations, the present study aimed to compare the color stability of two types of nanohybrid composites cured with QTH and LED devices after accelerated artificial aging (AAA). The null hypothesis was that the color stability of these composites is similar following polymerization with QTH and LED devices.

\section{Materials and Methods:}

In this in-vitro study, the color stability of two types of enamel and dentin nanohybrid composites (IPS Empress Direct, Ivoclar Vivadent, Schaan, Liechtenstein) was investigated. Twenty samples of enamel composite and 20 dentin composite specimens were randomly divided into two groups of 10 samples each. All samples were of A1 shade. To prepare composite specimens, discshaped metal molds $(10 \mathrm{~mm}$ in diameter and 2 $\mathrm{mm}$ in height) were used. The molds were placed on a glass slab. Then, the molds were filled with the composite, and another slab was placed over the Mylar strip on top of the mold. Uniform pressure was applied to even the composite distribution. Samples were then cured. A group of 10 samples of each composite was cured by the LED Bluephase light-curing device (Ivoclar Vivadent, Schaan, Liechtenstein) at $1200 \mathrm{~mW} / \mathrm{cm} 2$ for 20 seconds, and the other group of samples from each composite was cured by the QTH device (Coltolux, Colten, USA) at an intensity of $600 \mathrm{~mW} / \mathrm{cm} 2$ for 40 seconds. The intensity of both devices was evaluated by a radiometer before curing the samples. The samples were then extracted and polished by Sof-Lex Pop-On discs (3M ESPE, St. Paul, MN, USA). The initial color of the samples was determined by a Konica Minolta spectrophotometer (CS2000, USA) according to the CIE L*a*b* system. ${ }^{(7)}$ The composite samples were then subjected to an AAA process in the QUV/SPRAY device (USA). The specimens were exposed to ultraviolet (UV) radiation at $340 \mathrm{~nm}$ and $0.89 \mathrm{~W} / \mathrm{mm} 2$ for 8 hours at $60^{\circ} \mathrm{C}$ and then incubated in the dark at $100 \%$ humidity at $50^{\circ} \mathrm{C}$ for 4 hours. This process was performed intermittently for 384 hours, which corresponds to one year of restorative clinical service. The color of the samples was then reassessed.

Repeated-measures analysis of variance (ANOVA) was used to determine the effect of light-cure devices and composite type on the level of color component changes by considering the type of light-cure devices and composites as Between-Subjects Factor. In addition, two-way ANOVA was used to compare the level of color change in the study groups. The significance level was set at 0.05 .

\section{Results}

The data on the color change of the samples are presented in Table 1. There was a significant difference in color change between the samples cured by LED and QTH devices as the samples cured by the LED device showed less color change $(\mathrm{P}=0.047)$. However, the difference in color stability between enamel and dentin composites cured by a fixed device was not significant $(\mathrm{P}=0.474)$. Figure 1 shows the color change of the composite specimens following aging.

Table 1. Mean and standard deviation (SD) of color change in the studied composite resins.

\begin{tabular}{lll}
\hline Composite resin & QTH & LED \\
\hline IPS Empress Direct Enamel & $2.82 \pm 1.16^{\mathrm{Aa}}$ & $2.48 \pm 1.65^{\mathrm{Ab}}$ \\
\hline IPS Empress Direct Dentin & $3.92 \pm 2.46^{\mathrm{Aa}}$ & $2.21 \pm 1.03^{\mathrm{Ab}}$
\end{tabular}


*Different capital letters in the same column represent a statistically significant difference between the groups. Different lower case letters in the same line represent a statistically significant difference between the groups. LED=light-emitting diode, $\mathrm{QTH}=$ quartz-tungsten-halogen

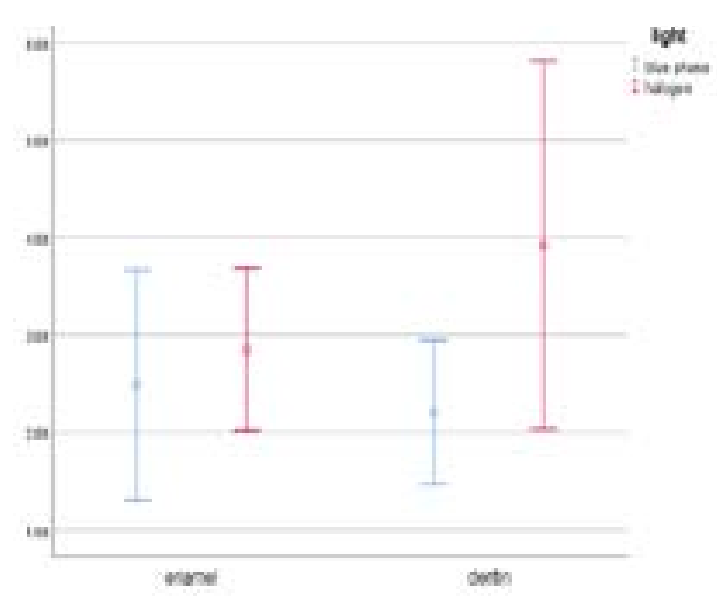

Figure 1. Color change of composites after aging

\section{Discussion}

The present study investigated the effect of light-curing device type on the color changes of two types of nanohybrid composite. The results showed that the use of the LED device improves color stability compared to the QTH device. Contrary to the results of the present study, Razavi et al showed that the use of QTH devices results in more color stability in microfilled composites compared to the LED. ${ }^{(8)}$ Sabatini reports no differences in the color stability of different composites cured with QTH or LED devices. (9) Sabatini showed that the color stability of composite resins was not different if different light-curing devices applied the same energy. ${ }^{(9)}$ In the present study, similar to the study by Sabatini, ${ }^{(9)}$ the curing time was 20 seconds in the LED groups and 40 seconds in the QTH groups. This difference in irradiation time was due to the difference in the intensity of the two devices to eventually transfer the same energy to the composite samples by both devices and make it possible to compare them. In a study by Elrashid et al, the highest color changes were observed in nanofilled composites cured with a QTH curing device, ${ }^{(10)}$ which was similar to the results of the present study. Pires-de-Souza et al also showed that the color change of hybrid composites cured by LEDs was lower than that of the samples cured by QTH devices. ${ }^{(1)}$ Alberton Da Silva et al showed that curing of nanofilled composites with higher intensity devices enhances color stability. ${ }^{(12)}$ This finding can be attributed to the increased degree of conversion (DC) following the use of higher intensity devices.

Various factors affect the DC of composites, including the size, type, and amount of filler particles, resin matrix composition, and amount of photoinitiator. ${ }^{(13)}$ As the DC of composite resins increases, the color stability improves. According to the results of Fourier transform infrared spectroscopy (FTIR), the highest DC was related to the TEGDMA monomer and the lowest to the BISGMA monomer. ${ }^{(14)}$ Therefore, the type of monomer of resin composites and the characteristics of the device used for curing affect the color stability of composite resins. ${ }^{(15)}$ The main monomer in the composites studied in the present research was BISGMA (15 weight percent).

The tendency to have whiter teeth is increasing among people. Therefore, today, different manufacturers are trying to produce lighter, less saturated composites to match with the color of lighter teeth. ${ }^{(16)}$ Camphorquinone photoinitiator, which is traditionally used in composites, has a yellow tint that reduces the compatibility of composites with light-colored teeth. ${ }^{(17,18)}$

New photoinitiators, such as Lucirin TPO, are used in composites to address this problem. ${ }^{(19)}$ The maximum photoabsorption and activation of camphorquinone are at 470 $\mathrm{nm}$ while the maximum absorption of Lucirin TPO initiator is at $390 \mathrm{~nm} .^{(20)}$ The photoinitiator of the composites studied in the present research is Lucirin TPO. These composites showed greater color stability when cured with the Bluephase curing device. The reason for this can be attributed to the fact that this device is a third-generation LED or polywave device that emits wavelengths in the range of 380 to 
$515 \mathrm{~nm}$; therefore, it can provide suitable curing for composites having initiators other than camphorquinone and thus reduces color change. ${ }^{(21)}$

LED devices are rapidly replacing QTH devices. This is due to faster and more efficient photopolymerization of composites following the use of these devices. ${ }^{(22)}$ Halogen devices can apply energy at constant power for 100 hours while new LED devices can work for up to 100,000 hours without reducing power. ${ }^{(23,24)}$ The output wavelength of LED devices is more consistent with the absorption spectrum of photoinitiators used in most composites compared to halogen devices. ${ }^{(22,25)}$ Another problem with QTH devices is the over-production of heat during operation, which causes the internal components of the device, such as filters and reflectors, to rapidly degrade in performance. ${ }^{(26,27)}$ Therefore, these devices require regular repair, which is timeconsuming and expensive. Another problem with these devices is their large size. In contrast, LED devices are better sized and designed, consume less energy, and last longer. ${ }^{(27)}$ These devices also resulted in greater color stability in the tested composites in the present study. Investigation of other properties of composites cured with QTH devices or LEDs is recommended in future studies.

\section{Conclusion}

Considering the limitations of this in-vitro study, curing nanohybrid composites with the Bluephase LED device causes less color change compared to QTH devices.

\section{Acknowledgments}

This study has been derived from a student thesis supported by the Islamic Azad University of Medical Sciences. The authors thank the Islamic Azad University of Medical Sciences and the Dental Research Center of Tehran University of Medical Sciences.

The authors deny any conflict of interest.

\section{References}

1. Catelan A, Briso AL, Sundfeld RH, Dos Santos PH. Effect of artificial aging on the roughness and microhardness of sealed composites. J Esthet Restor Dent. 2010 Oct;22(5):324-30.

2. Aguilar FG, Roberti Garcia Lda F, Cruvinel DR, Sousa AB, de Carvalho Panzeri Pires-de-Souza F. Color and opacity of composites protected with surface sealants and submitted to artificial accelerated aging. Eur J Dent. 2012 Jan;6(1):24-33.

3. Gaintantzopoulou M, Kakaboura A, Vougiouklakis G. Colour stability of tooth-coloured restorative materials. Eur J Prosthodont Restor Dent. 2005 Jun;13(2):51-6.

4. Falkensammer F, Arnetzl GV, Wildburger A, Freudenthaler J. Color stability of different composite resin materials. J Prosthet Dent. 2013 Jun;109(6):37883.

5. Price RB, Ehrnford L, Andreou P, Felix CA. Comparison of quartz-tungsten-halogen, light-emitting diode, and plasma arc curing lights. J Adhes Dent. 2003 Fall;5(3):193-207.

6. Choudhary S, Suprabha B. Effectiveness of light emitting diode and halogen light curing units for curing microhybrid and nanocomposites. J Conserv Dent. 2013 May-Jun; 16(3): 233-7.

7. Hoorizad Ganjkar M, Heshmat H, Gholamisinaki M, Emami Arjomand M. Effect of Accelerated Aging on the Color Stability of Light-cured Res-in Cement and Flowable Composite Through Porcelain Laminate Veneer. J Islam Dent Assoc Iran. 2017; 29 (3) :103-109.

8. Razavi S, Esmaeili B, Amiri H, Pakdaman M, Bijani A. Color stability of a microhybrid resin composite polymerized with LED and QTH light curing units. J Dentomaxillofac Radiol Pathol Surg. 2014;2(4):7-14. 9. Sabatini C. Color Stability Behavior of Methacrylate-based Resin Composites Polymerized with Light-emitting Diodes and Quartz-Tungsten-Halogen. Oper Dent. 2015 May-Jun;40(3):271-81.

10. Elrashid AH, Barri GM, Alnafea MA, Alanezi SE, Alhabdan HA. Color Stability of aesthetic composite restoration using LED and halogen light cure. Int J Appl Dent Sci. 2018;4(1):12-16.

11. Pires-de-Souza Fde C, Garcia Lda F, Hamida HM, Casemiro LA. Color stability of composites subjected to accelerated aging after curing using either a halogen or a light emitting diode source. Braz Dent J. 2007;18(2):119-23.

12. Alberton Da Silva V, Alberton Da Silva S, Pecho OE, Bacchi A. Influence of composite type and light irradiance on color stability after immersion in different beverages. J Esthet Restor Dent. 2018 Sep;30(5):390-6.

13. Leonard DL, Charlton DG, Roberts HW, Cohen 
ME. Polymerization efficiency of LED curing lights. J Esthet Restor Dent. 2002;14(5):286-95.

14. Sideridou I, Tserki V, Papanastasiou G. Effect of chemical structure on degree of conversion in lightcured dimethacrylate-based dental resins. Biomaterials. 2002 Apr;23(8):1819-29.

15. Stansbury JW. Dimethacrylate network formation and polymer property evolution as determined by the selection of monomers and curing conditions. Dent Mater. 2012 Jan;28(1):13-22.

16. Carey CM. Tooth whitening: what we now know. J Evid Based Dent Pract. 2014 Jun;14 Suppl:70-6.

17. Brandt WC, Schneider LF, Frollini E, Correr-Sobrinho L, Sinhoreti MA. Effect of different photo-initiators and light curing units on degree of conversion of composites. Braz Oral Res. 2010 JulSep;24(3):263-70.

18. Sim JS, Seol HJ, Park JK, Garcia-Godoy F, Kim HI, Kwon YH. Interaction of LED light with coinitiator-containing composite resins: effect of dual peaks. J Dent. 2012 Oct;40(10):836-42.

19. Randolph LD, Palin WM, Bebelman S, Devaux J, Gallez B, Leloup G, et al. Ultra-fast light-curing resin composite with increased conversion and reduced monomer elution. Dent Mater. 2014 May;30(5):594604.

20. Rueggeberg FA. State-of-the-art: dental photocuring--a review. Dent Mater. 2011 Jan;27(1):39-52.

21. Rueggeberg FA, Swift EJ Jr. Exposure times for contemporary composites. J Esthet Restor Dent. 2013 Apr;25(2):82-4.

22. Jandt KD, Mills RW. A brief history of LED photopolymerization. Dent Mater. 2013 Jun;29(6):60517.

23. Jadhav S, Hegde V, Aher G, Fajandar N. Influence of light curing units on failure of directcomposite restorations. J Conserv Dent. 2011 Jul-Sep; 14(3):225-7. 24. Polydorou O, Manolakis A, Hellwig E, Hahn P. Evaluation of the curing depth of two translucent composite materials using a halogen and two LED curing units. Clin Oral Investig. 2008 Mar;12(1):45-51.

25. Rencz A, Hickel R, Ilie N. Curing efficiency of modern LED units. Clin Oral Investig. 2012 Feb;16(1):173-9.

26. Nemati Anarakiu S, Kazemi H, GHafari Z, Naser Z, Bitaraf T. In-Vitro Comparative Study of the Effect of Four Finishing and Polishing Tools on Surface Roughness of a Microhybrid Resin Composite. J Res Dentomaxillofac Sci. 2019;4 (2): 26-31.

27. Mills RW, Uhl A, Blackwell GB, Jandt KD. High power light emitting diode (LED) arrays versus halogen light polymerization of oral biomaterials: Barcol hardness, compressive strength and radiometric properties. Biomaterials. 2002 Jul;23(14):2955-63.
Please cite this paper as: Fakhari A, Heshmat H, Emami Arjomand M, Tabatabaei S. Influence of Light-Curing Units on Color Stability of Composite Resins After Aging. J Res Dentomaxillofac Sci. 2020; 5 (2) :21-25 